\title{
Rotavirus and its Genotype Distribution among Children Less than Three Years Presenting with Acute Watery Diarrhoea to a General Hospital in Urban Nepal
}

\author{
Shrestha $\mathbf{S}^{1}$, Upadhyay $\mathrm{B}^{2}$, Limbu $\mathrm{B}^{3}$, Pradhan $\mathrm{R}^{4}$, Nakagomi Tokoko ${ }^{5}$, Thorson $\mathbf{S}^{6}$, Pollard AJ $\mathrm{J}^{7}$ Adhikari $\mathbf{N}^{8}$
}

${ }^{1}$ Dr. Shrijana Shrestha, MBBS. MD. Professor Department of Paediatrics, Paediatric Research Unit, Department of Paediatrics, Patan Hospital, Patan Academy of Health Sciences, Kathmandu, Nepal, ${ }^{2}$ Dr. Bishwas Upadhyay, MBBS. Paediatric Research Unit, Department of Paediatrics, Patan Hospital, Patan Academy of Health Sciences, Kathmandu, Nepal, ${ }^{3}$ Dr. Bhupendra Limbu, MBBS, Paediatric Research Unit, Department of Paediatrics, Patan Hospital, Patan Academy of Health Sciences, Kathmandu, Nepal, ${ }^{4}$ Dr. Rahul Pradhan, MBBS, Paediatric Research Unit, Department of Paediatrics, Patan Hospital, Patan Academy of Health Sciences, Kathmandu, Nepal, ${ }^{5}$ Dr. Toyoko Nakagomi, MD, PhD. Division of Molecular Epidemiology, Department of Molecular Microbiology and Immunology, Graduate School of Biomedical Sciences, Nagasaki University, ${ }^{6}$ Dr. Stephen Thorson, MD, Paediatric Research Unit, Department of Paediatrics, Patan Hospital, Patan Academy of Health Sciences, Kathmandu, Nepal, ${ }^{7}$ Dr. Andrew J. Pollard, FRCPCH, PhD Oxford Vaccine Group, University Department of Paediatrics, University of Oxford, Oxford, United Kingdom, ${ }^{8}$ Dr. Neelam Adhikari, MD. Professor in Paediatrics. Paediatric Research Unit, Department of Paediatrics, Patan Hospital, Patan Academy of Health Sciences, Kathmandu, Nepal.

Address for correspondence: Dr. Shrijana Shrestha, E-mail: shri_rishi@hotmail.com

\begin{abstract}
Introduction: Viruses are the most common cause for diarrhoea in infants and small children. Rotavirus is the most frequent viral etiology, causing 125 million episodes of infantile diarrhoea and over 600,000 deaths per year. Materials and methods: A cross sectional study between January and March 2008 was conducted at Patan Hospital, Kathmandu to find out the prevalence of rotavirus among children $<3$ years with watery diarrhoea and to identify common strains of rotavirus in the study population. Testing for rotavirus was undertaken by using Rota/Adeno screen Dipstick M583CE. Rotavirus strain identification was done at Nagasaki University Japan. Data was analyzed using SPSS $®$ for Windows V 15.0 software. Results: 119 children with acute watery diarrhoea were enrolled. Rotavirus antigen was found in 63 cases (53\%). The highest percentage of rotavirus infection was found in the second six months of life. Among the children with positive rotavirus antigen, the median age was 10 months (IRQ 8.00). The most predominant strain of rotavirus identified was $\mathrm{G} 12$ followed by $\mathrm{G} 9$ and $\mathrm{G} 1$. Most predominant $\mathrm{G}$ and $\mathrm{P}$ combination was G9 P[8] followed by G12P[6]. Conclusion: The study has shown the prevalence of unusual serotypes of rotavirus. Though rotavirus vaccine has been studied, used widely and found to be very effective, none of the vaccine efficacy studies have included common serotypes identified in Nepal. Level of protection conferred by infant immunization with the current rotavirus vaccines against the strains circulating in Nepal is unknown and careful surveillance through vaccine implementation is needed.
\end{abstract}

Key words: Diarrhoea, Nepal, rotavirus, rotavirus genotypes, vaccine

\section{Introduction}

$\mathrm{D}$ arrhoeal disease remains the second most common cause of death in children less than five years of age worldwide and viruses are common cause of diarrhoeal diseases in infants and small children.

Rotavirus is the most frequent virus identified, causing 125 million episodes of infantile diarrhoea and over 600,000 deaths per year. The highest mortality occurs in the poorest countries ${ }^{1,2}$. In the prevaccine era rotavirus 
infected almost all children before their $5^{\text {th }}$ birthday ${ }^{1,2}$. The incidence of rotavirus infection is equal in both developed and developing countries. In spite of the efforts to improve sanitation and hygiene, the rates of rotavirus diarrhoea have remained relatively stable over time $^{3}$. Rotavirus is not often viewed as a priority and is incorrectly considered a disease that can be prevented by improvements in water and sanitation ${ }^{4}$.

The economic burden of this disease is very high. It is estimated that in Asia alone vaccination could potentially save lives of 109,000 children; prevent 1.4 million hospital admissions,7.7 million OPD visits; and decrease the healthcare cost by US $\$ 191$ million $^{5}$. Therefore, WHO encourages rotavirus vaccination to counter this disease burden. Rotavirus vaccine has been targeted for inclusion in the National Immunisation Programs in both developed and developing countries. With this view the Asian Rotavirus Surveillance Network (ARSN) has been collecting data from developing countries and the Global Alliance for Vaccination and Immunisation (GAVI) is willing to provide vaccine to certain eligible countries ${ }^{6}$. Nepal is also a GAVI-eligible country, and is participating in ARSN.

Rotaviruses are non-enveloped RNA virus. The genes encoding the outer capsid viral proteins

VP7 and VP4 form the basis for classification of rotaviruses into $\mathrm{G}$ and $\mathrm{P}$ genotypes, respectively. These proteins are considered critical to vaccine development because they are targets for neutralizing antibodies that are believed to be important for protection ${ }^{7}$. G1, G2, $\mathrm{G} 3$, and $\mathrm{G} 4$ rotavirus types in conjunction with $\mathrm{P}[8]$ or $P$ [4] constitute nearly $90 \%$ of the rotavirus infections worldwide $^{8}$. The current available vaccines provide a high degree of protection against G1 wild-type and strains G2, G3, G4 and G99.

A multicentric trial in South Africa and Malawi has concluded that rotavirus vaccine significantly reduced the incidence of severe rotavirus gastroenteritis in African infants $(61.2 \%)$ however the overall efficacy was lower than that observed in European and Latin American Studies (96.4\% and $84.8 \%$ respectively). In this African study the circulating rotavirus strains were diverse and less well matched to the vaccine with only $12.9 \%$ of the rotavirus strains in Malawi being G1P [8], perhaps accounting for the lower efficacy ${ }^{10}$.

In this study we assessed the prevalence of rotavirus disease among children $<3$ years of age in urban Nepal presenting with watery diarrhoea and identified the common strains of rotavirus in our population.

\section{Materials and Methods}

We undertook a prevalence study at Patan Hospital in Kathmandu from January to March 2008.

Patan Hospital is a 450 bedded general hospital located within Kathmandu valley and the second largest children's service in the city. Annually over 40,000 children are seen in outpatient clinics and around 3,000 children are admitted to the children's ward.

Children under 3 years of age presenting to Paediatric outpatient clinics or admitted to children ward with acute watery diarrhoea were visited by a Paediatric research fellow. After informed parental consent, a data collection form was completed and a stool sample was collected. Testing for rotavirus and adenovirus was undertaken by the research fellow using Rota/Adeno screen Dipstick M583CE (Microgen Bioproducts Ltd, Surrey, UK). Rota/Adeno screen Dipstick is an immune chromatographic test where the dipstick detects the colour changes coming in contact with the positive stool sample. When possible, the stool sample was sent for routine microscopy. A portion of each stool sample was stored at $-70^{\circ}$ Celsius for strain identification later in Japan.

The stool samples with positive rotavirus dipstick were collected by the big rotavirus surveillance study at Tribhuvan University Teaching Hospital, Nepal and were sent to Japan. Rotavirus strain identification was done at Nagasaki University, Japan. The G and P types for rotavirus positive specimens were determined by the polymerase chain reaction amplification method described by Gouvea et al and Gunasena et al. ${ }^{11,12}$ Data was analyzed using SPSS ${ }^{\circ}$ for Windows V 15.0 software. Percentage distribution, descriptive statistics, odds ratio along with its $95 \%$ confidence interval were used for the analysis.

The study was approved by Nepal Health Research Council; Ref. 620.

\section{Results}

A total of 119 children ( $71 \%$ male) with acute watery non-bloody diarrhoea were enrolled and stool samples collected. The median age was found to be 10 months with IQR of 10 months. The highest number of patients enrolled was in the age group 6 to 12 months $(38.7 \%)$ Out of 119 stool samples rotavirus antigen alone was found to be present in 63 cases (53\%) and adenovirus antigen alone in 4 cases $(3.4 \%)$, and both rotavirus and adenovirus antigen in 2 cases $(1.7 \%)$. The highest percentage of rotavirus infection was found in 
the second six months of life. Rotavirus antigen was positive in $61 \%$ of the children in the age group of 6 to 12 months, $51 \%$ of the children in the age group of 12 to 24 months and $48 \%$ of children in the age group less than 6 months which contributed to $44 \%, 30 \%$ and $18 \%$ of the total rotavirus positive cases in the study respectively. (Table 1) Among the children with positive rotavirus antigen, the median age was 10 months (IQR 8.00).

The most common symptoms at presentation apart from diarrhoea among the children enrolled were fever $(22.6 \%)$, vomiting $(81.5 \%)$ and mild to moderate dehydration (98.3\%). (Table:2) Rotavirus infection was more common in children with vomiting than those without this symptom (Odds ratio 1.76, 95\% Cl: $1.24-$ 2.50).

Results of stool routine microscopy were available in 81 cases. Of these 25 had white blood cells in stool, but only 4 patients had a white blood cell count of more than 10 per high power field and all 4 were negative for rotavirus antigen. Eight out of 81 stool samples showed cyst of Entaeomeba histolytica, and 2 showed yeast cells.

Most of the cases of watery diarrhoea were managed on an outpatient basis (81.5\%) and only 22 (8.5\%) were admitted. Of the 22 admitted cases, 13 $(59 \%)$ were positive for rotavirus. The most common reason for admission was persistent vomiting. The median length of hospitalization was 3 days with IQR of 5 days.

The most predominant strain of Rota virus identified was $\mathrm{G} 12$ followed by $\mathrm{G} 9$ and $\mathrm{G} 1$. The predominant $\mathrm{G}$ and P combination was G9P8 followed by G12 P[6]. There were only 4 specimens for which we were unable to assign $P$ types (Table: 3 ).

Table 1: Showing distribution of Rotavirus by Age Groups.

\begin{tabular}{|l|c|c|c|}
\hline \multirow{2}{*}{ Age Group } & \multicolumn{2}{|c|}{ Rotavirus Status (Dipstick) } & \multirow{2}{*}{ Total } \\
\cline { 2 - 3 } & Yes & No & $23(100 \%)$ \\
\hline $0-6$ months & $11(47.8 \%)$ & $12(52.2 \%)$ & $46(100 \%)$ \\
\hline $6-12$ months & $28(60.9 \%)$ & $18(31.1 \%)$ & $37(100 \%)$ \\
\hline $12-24$ months & $19(51.4 \%)$ & $18(48.6 \%)$ & $13(100 \%)$ \\
\hline $24-36$ months & $5(38.5 \%)$ & $8(61.5 \%)$ & $\mathbf{1 1 9 ( 1 0 0 \% )}$ \\
\hline \multicolumn{1}{|c|}{ Total } & $\mathbf{6 3 ( 5 3 \% )}$ & $\mathbf{5 6 ( 4 7 \% )}$ & \\
\hline
\end{tabular}

Chi-square $=2.534, p$-value $=0.469$

Table 2: Showing clinical features in rotavirus antigen positive and negative cases.

\begin{tabular}{|l|c|c|c|}
\hline Clinical features & Rotavirus antigen +ve & Rotavirus antigen -ve & $\boldsymbol{p}$ value \\
\hline Fever & $15 / 63(23.8 \%)$ & $12 / 56(21.42 \%)$ & 0.757 \\
\hline Nausea & $9 / 63(14.28 \%)$ & $9 / 56(16.07 \%)$ & 0.786 \\
\hline Vomiting & $57 / 63(90.47 \%)$ & $40 / 56(71.42 \%)$ & 0.008 \\
\hline Dehydration & $56 / 63(88.88 \%)$ & $48 / 56(85.71 \%)$ & 0.869 \\
Mild & $6 / 63(9.5 \%)$ & $7 / 56(12.5 \%)$ & \\
Moderate & $1 / 63(1.58 \%)$ & $1 / 56(1.78 \%)$ & \\
Severe & \multicolumn{2}{|}{} \\
\hline
\end{tabular}

Table 3: Showing Identified Strains of Rotavirus (total $n=63$ )

\begin{tabular}{|l|c|c|c|}
\hline & P 6 & P 8 & P non typable \\
\hline G 1 & $8(13 \%)$ & $3(5 \%)$ & 0 \\
\hline G 3 & $2(3 \%)$ & $4(6 \%)$ & 0 \\
\hline G 9 & $1(2 \%)$ & $17(27 \%)$ & $2(3 \%)$ \\
\hline G 12 & $13(21 \%)$ & $10(16 \%)$ & $\mathbf{0}$ \\
\hline G non typable & $\mathbf{1 ( 2 \% )}$ & $\mathbf{0}$ & $\mathbf{4 ( 6 \% )}$ \\
\hline Total & $\mathbf{2 5 ( 4 0 \% )}$ & $\mathbf{3 4}(\mathbf{5 4} \%)$ & \\
\hline
\end{tabular}




\section{Discussion}

Our study confirms that rotavirus infection is one of the most important causes of watery gastroenteritis in children in Kathmandu. Infants and children with rotavirus gastroenteritis are likely to have more severe symptoms than those with non-rotavirus gastroenteritis ${ }^{13}$. In this study in urban Nepal rotavirus infection was present in over $56 \%$ of cases of watery diarrhoea, and was especially common in young infants less than a year of age. In a previous study undertaken in Nepal in children with acute diarrhoea attending a rehydration clinic at Kanti Children's Hospital, a large paediatric hospital in Kathmandu, from August 2004 through July 2005, $23.3 \%$ were positive for rotavirus antigen ${ }^{14}$. The study also reported a seasonal variation in the occurrence of rotavirus diarrhoea with a peak in January; and a monthly prevalence of rotavirus detection varying from $7.3 \%$ to $58.6 \%$. Rotavirus infection has a peak in winter in temperate climate and this is likely to be one of the reasons for the high proportion of positive cases in our study. One limitation of our study is the short duration of surveillance and therefore the limited sample size.

As in other studies we saw that rotavirus infection was most common less than 1 year of age. Although children can be infected with rotavirus several times during their lives, initial infection after age 3 months is most likely to cause severe gastroenteritis and dehydration ${ }^{15}$. A previous study in Nepal found that $64 \%$ of rotavirus positive diarrhoea cases occurred in infant aged 3 to 23 months. ${ }^{14}$ In a study at Kanti Children Hospital, the prevalence of nosocomial infection due to rotavirus among children aged 3-59 months was $30.2 \%^{16}$.

Where rotavirus disease burden is high, vaccination is the most effective means to reduce morbidity and mortality. In our study, 59\% of patients admitted for watery diarrhoea had rotavirus diarrhoea. Proper vaccine implementation would likely reduce health care costs and societal costs substantially.

The prevalent $G$ and $P$ serotypes of rotavirus vary in different parts of the world and it has been observed that there is also variation in different parts of Asia ${ }^{6}$. In the present study the most prevalent $G$ and $P$ serotypes are $\mathrm{G} 12(40 \%)$ and $\mathrm{P} 8$ (25\%). The most prevalent combination of $G$ and $P$ serotypes in this study are $G 9$ P[8] (25\%) followed by G12 P[6]. In a study conducted at Tribhuvan University Teaching Hospital (TUTH), Nepal in 2005-2006 and in 2006-2007 most prevalent serotypes were G12 (50\% and 29\%) and P8 (47\% and $35 \%)$ with the most prevalent combination serotype G12P6 (34\% and 24\%) $)^{17}$.
A surveillance study in Nepal during 2003-2004 showed the emergence of $\mathrm{G} 12$ strains $^{18}$. Another study carried out in 2004-2005 also found G12 as one of the common serotypes ${ }^{14}$. The prevalence of the strain G12 in the $2003-2004$ study was $20 \%$ with either $\mathrm{P}[6]$ or $\mathrm{P}[8]^{18}$ while in the present study $\mathrm{G} 12$ accounts for $40 \%$ of the strains. The G12 strain of rotavirus was first detected in India in 2001 and has emerged as the predominant strains in Delhi, India, during 2005 to $2007^{19}$. In a study done in Bangladesh in 2005-2006, the prevalence of G12P[6] was $11 \%{ }^{20}$.

The emergence and increase in G12 and non-P[8] strains may challenge the current rotavirus vaccination strategy, the efficacy of which has not been well studied against these newer strains. In a large Latin American study, oral rotavirus vaccine efficacy was observed in both $\mathrm{G} 1$ and non-G1 strains with $\mathrm{P}[8]$ specificity ${ }^{21}$. However, a recent pooled analysis showed that the monovalent rotavirus vaccine is cross-protective against non-G1P[8] strains and provides significant protection against gastroenteritis caused by different circulating rotaviruses (G1/non-G1 and $P[8]$, and non-G1-non$P[8])^{22}$. However none of these studies included the common genotypes identified in Nepal like G12 or P[6] as these genotypes were not in circulation in the areas where vaccine efficacy studies were carried out.

\section{Conclusion}

Rotavirus is a significant cause for diarrhoea in children presenting to Patan Hospital during the months of January to March with disease burden especially prominent in the second six months of life $(62.2 \%)$. The most common combination serotypes of rotavirus in our study (G9 P[8] followed by G12 P[6]) differed from those identified in developed countries but were comparable to previous studies done in Nepal. The higher prevalence of $\mathrm{G} 12(40 \%)$ in the present study compared to $20 \%$ in a previous study in 2003-2004 suggests that G12 strain is likely to be increasing among the circulating rotavirus strain in our population and study setting. This is a small study within a short period of time and the data needs to be verified with the ongoing bigger surveillance studies being carried out under ARSN.

Reccommendation: This study confirms the need for control of rotavirus through immunization as it is a major cause of morbidity and hospitalization in Nepal. However, the level of protection conferred by infant immunization with the current rotavirus vaccines against the strains circulating in Nepal is unknown and careful surveillance through vaccine implementation is needed.

Acknowledgement: We are grateful to Mr. Shital 
Bhandary, PAHS, for his help in statistical analysis. Mr T. Iriye, Mr. S. Tsuji, and Mr. T. Okamura, Nagasaki University, Japan, for laboratory support and stain identification Professor David Murdoch, University of Otago and Professor Osamu Nakagomi, University of Liverpool for reviewing the article The Oxford Vaccine Group who provided funding for the antigen detection kits and to Dr N Cunliffe, Liverpool, for helping us make the initial contacts for the study and to the NIHR Oxford Biomedical Research Unit who support AJPollard.AJP is a Jenner Institute Investigator and James Martin Senior Fellow.

Potential Conflicts of Interests: AJ Pollard acts as chief investigator for clinical trials conducted on behalf of Oxford University sponsored by vaccine manufacturers, including manufacturers of rotavirus vaccines, but does not receive any personal payment from them. Oxford University receives unrestricted educational grants for organization of educational activities by AJP, which are paid directly to an educational/administrative fund held by the Department of Paediatrics, University of Oxford. The other authors have no potential conflicts of interests to declare.

Funding organization: University Department of Pediatrics Room, 02-46-03 Level 2, Children's Hospital (John Radcliffe), Headley Way, Headington, Oxford OX3 9DU.

\section{References}

1. Parasar UD, Hummelman EG, Bresee JS, Miller MA, Glass RI. Global illness and deaths caused by rotavirus disease in children. Emerg Infect Dis 2003;9(5):565-72.

2. Parashar UD, Gibson CJ, BreseeJS, Glass RI. Rotavirus and severe childhood diarrhea. Emerg Infect Dis 2006:12(2):304-6.

3. Glass RI, BreseeJS, Turcios R, Fischer TK, Parashar UD, Steele AD. Rotavirus vaccines: targeting the developing world. J Infect Dis 2005;192(Suppl. 1):S160-6.

4. Bresee J, Fang Z Y, Wang B, Nelson EAS, Tam $J$, Soenarto $Y$ et al. First Report from the Asian Rotavirus Surveillance Network. Emerg Infect Dis 2004;10:988-95.

5. Podewils LJ, Antil L, Hummelman E, Bresee J, Parashar UD, Rheingans R. Projected cost effectiveness of rotavirus vaccination for children in Asia. J Infect Dis 2005;192(Suppl.1):S133-45.
6. Santoshan M, Nelson E A S, Bresee J S. Implementing rotavirus vaccination in Asia. Vaccine 2007; 25: 7711-16.

7. Estes MK, Kapikian AZ. Rotaviruses. In: Knipe DM, Howley PM, eds. Field's Virology. 5th ed. Philadelphia, PA: Lippincott Williams and Williams; 2007:1917-58.

8. Santos N, Hoshino Y. Global distribution of rotavirus serotypes/genotypes and its implication for the development and implementation of an effective rotavirus vaccine. Rev Med Virol 2005;19:29-56.

9. Vesikari T, Karvonen A, Prymula R, Schuster V, Tejedor JC, Cohen R et al. Efficacy of human rotavirus vaccine against rotavirus gastroenteritis during the first 2 years of life in European infants: randomized, double-blind controlled study. Lancet 2007;370:1757-763.

10. Madhi SA, Cunliffe NA, Steele D, Witte D, Kirsten $M$, Louw $C$ et al. Effect of Human rotavirus vaccine on severe diarrhea in African infants. N Engl J Med 2010;362:289-98.

11. Gouvea V, Glass RI, Wood P, Taniguchi K, Clark $\mathrm{HF}$, Forreter $\mathrm{B}$ et al. Polymerase chain reaction amplification and typing of rotavirus nucleic acid from stool specimens. J. Clin. Microbiol 1990;28:276-82.

12. Gunasena S, Nakagomi O, Isegawa $\mathrm{Y}$, Kaga $\mathrm{E}$, Nakagomi T, Steele AD et al. Relative frequency of VP4 gene alleles among human rotavirus recovered over a 10-year period (1982-1991) from Japanese children with diarrhea. J Clin Microbiol 1993;31:2195-197.

13. Kovacs A, Chan L, Hotrakitya C, Overturf G, Portnoy B. Rotavirus gastroenteritis: clinical and laboratory features and use of the Rotazyme test. Am J Dis Child 1987;141:161-66.

14. Pun SB, Nakagomi T, Sherchan JB, Pandey BD, Cuevas LE, Cunliffe NA et al. Detection of G 12 human rotavirus in Nepal. Emerg Infect Dis 2007;13:482-83.

15. Velazquez FR, Matson DO, Calva JJ, Guerrero ML, Morrow AL, Campbell SC et al. Rotavirus infection in infants as protection against subsequent infections. N Engl J Med 1996;335:1022-028.

16. Sherchan JB, Ohara H, Sherpa K, Sakurada S, Gurung B, Tandukar S etal.Rotavirus Nosocomial infection in Children under 5 years of age: a preliminary study in Nepal. J Nepal Paediatr Soc 2011;31(1):30-34. 
17. Sherchand JB, Nakagomi O, Dove W, Nakagomi T, Yokoo M, Pandey BD et al. Molecular epidemiology of rotavirus diarrhea among children aged <5years in Nepal: Predominance of emergent G12 strains during 2 years. J Infect Dis 2009;200(Suppl.1):S182-87.

18. Uchida R, Pandey BD, Sherchand JB, Ahmed K, Yokoo M, Nakagomi T et al. Molecular epidemiology of rotavirus diarrhea among children and adults in Nepal: detection of $\mathrm{G} 12$ strains with $\mathrm{P}[6]$ or $\mathrm{P}[8]$ and a G11P[25] strain. J Clin Microbiol 2006;44:3499505.

19. Sharma S, Ray P, Gentsch JR, Glass RI, Kalra $\mathrm{V}$, Bhan MK. Emergence of $\mathrm{G} 12$ rotavirus strains in Delhi, India, in 2000 to 2007. J Clin Microbiol 2008;46:1343-348.
20. Rahman M, Sultana R, Ahmed G, Nahar S, Hassan ZM, Saiada F et al. Prevalence of G2P[4] and $\mathrm{G} 12 \mathrm{P}[6]$ rotavirus, Bangladesh. Emerg Infect Dis 2007;13:18-24.

21. Linhares AC, Velázquez FR, Pérez-Schael I, SaezLlorens X, Abate H, Espinoza $\mathrm{F}$ et al. Efficacy and safety of an oral live attenuated human rotavirus vaccine against rotavirus gastroenteritis during the first 2 years of life in Latin American infants: a randomised, double-blind, placebo-controlled phase III study. Lancet 2008;371:1181-189.

22. De Vos B, Han HH, Bouckenooghe A, Debrus S, Gillard $P$, Ward $R$ et al. Live attenuated human rotavirus vaccine, RIX4414, provides clinical protection in infants against rotavirus strains with and without shared $G$ and $P$ genotypes: integrated analysis of randomized controlled trials. Pediatr Infect Dis J 2009;28:261-66.

\section{How to cite this article?}

Shrestha S, Upadhyay B, Limbu B, Pradhan R, Nakagomi Tokoko, Thorson S, Pollard AJ, Adhikari N. Rotavirus and its Genotype Distribution among Children Less than three years Presenting with Acute Watery Diarrhea to a General Hospital in Urban Nepal. J Nep Paedtr Soc 2011;31(2):110-115. 